\title{
Study of Erectile Dysfunction in Prediabetes
}

\section{Gaurav Jagtap ${ }^{1}$, T K Kamble², Sunil Kumar³, Y.U. Chitriv ${ }^{4}$}

\section{IJCRR}

Section: Healthcare

Sci. Journal Impact

Factor: $6.1(2018)$

ICV: 90.90 (2018)

(c) (7) (5)

Copyright@IJCRR
Postgraduate Resident, Department of Medicine, Jawahar Lal Nehru Medical College, Datta Meghe Institute of Medical Sciences (Deemed University), Sawangi, Wardha, Maharashtra, India; ${ }^{2}$ Professor- Department of Medicine, ]awahar Lal Nehru Medical College, Datta Meghe

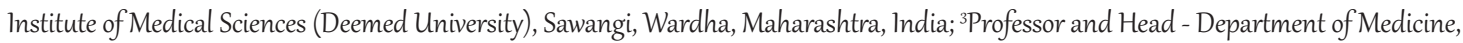
Jawahar Lal Nehru Medical College, Datta Meghe Institute of Medical Sciences (Deemed University), Sawangi, Wardha, Maharashtra, India; ${ }^{4}$ Professor, Electronics \& Tele. Engineering, Yeshwantrao Chavan College of Engineering, Nagpur, Maharashtra, India.

\section{ABSTRACT}

Background: Diabetes is a setup chance factor for sexual dysfunction in men; a triple expanded danger of erectile dysfunction (ED) was archived in diabetic contrasted with nondiabetic men. Risk of ED had not been studied in Pre-Diabetics. This study had been planned to see Erectile Dysfunction prevalence in patients diagnosed with Prediabetes.

Objectives: To correlate erectile dysfunction with cardiovascular risk factors in patients of prediabetes.

Methods: This cross-sectional research study will be directed in the department of general medicine between august 2019 to September 2021. Cases will be selected by set questionnaires amongst prediabetes patients and controls will be selected as age and sex-matched normoglycemic patients.

Expected Results: Prediabetes may be associated with the risk of erectile dysfunction.

Key Words: Prediabetes, Erectile dysfunction, Testosterone

\section{INTRODUCTION}

As indicated by the International Diabetes Federation in 2017, in the world, Diabetes Mellitus had to be expected in 451 individuals. Its commonness is expanding quickly and by 2045, this number is assessed to be 693 million. As showed by international diabetes federation atlas, in India in 2017 there were 72.9 million cases of DM. Dysfunction of cardiac autonomic activity is seen as related with prediabetes, reflected by diminished parasympathetic modulation of the heart, reduced heart rate variability and expanded prevalence of erectile dysfunction in males. ${ }^{1}$ Data from non-diabetic male have revealed a contrary connection between the resistance of insulin and testosterone concentration. ${ }^{2,3}$ This raised the issue of whether prediabetes, a state of extended resistance of insulin is furthermore associated with diminishing testosterone level, which leads to erectile dysfunction. ${ }^{4,5}$ With this background literature in mind, we intended to study erectile dysfunction in prediabetes. All prediabetic patients should be screened for neuropathy. ${ }^{6,7}$ They conclude that prediabetes is a danger factor for growing up of neuropathy related to hyperglycaemia being acting by methods for the similar path as if there should be an occurrence of diabetes. Patients of prediabetes are in danger of fully developed neuropathy. In the present study we aimed to correlate erectile dysfunction with cardiovascular risk factors in patients of prediabetes

\section{MATERIALS AND METHODS}

This Cross-sectional research study will be directed in the department of general medicine in Jawaharlal Nehru Medical College at Central India from August 2019 to September 2021. The cases will be selected who will fulfil the World Health Organization (WHO) criteria for prediabetes such as Impaired fasting glucose (IFG) characterized as fasting plasma glucose (FPG) of 110 to $125 \mathrm{mg} / \mathrm{dl}(6.1-6.9 \mathrm{mmol} / \mathrm{L})$ or Plasma glucose level after two hours after administration of $75 \mathrm{~g}$ Oral Glucose Tolerance Test (GTT) is between 140 and $199 \mathrm{mg} / \mathrm{dL}$ orHBA1C level $5.7-6.5 \%$ and whose age more than 18 years.

The patients will be excluded with history of diabetes mellitus, cirrhosis of the liver, HIV, pancreatitis, primary testicu-

\section{Corresponding Author:}

Dr. Gaurav Jagtap, Department of Medicine, Jawahar Lal Nehru Medical College, Datta Meghe Institute of Medical Sciences (Deemed University), Sawangi, Wardha, Maharashtra, India; Contact: 9284758840; Email: gauravjagtap12@gmail.com

ISSN: 2231-2196 (Print)

Received: 07.09.2020
ISSN: $0975-5241$ (Online)

Revised: 14.10 .2020
Accepted: 08.11 .2020 
lar failure, the disorder of pituitary gland itself and testicular cancer and cases often having hormone (androgen/testosterone) replacement treatment or androgen decreasing therapy or radiation beam therapy and Patient with kidney disease (Chronic Kidney Disease, Acute Kidney Injury) and controls will be selected as age and sex-matched normoglycemic patients.

The patients, diagnosed as prediabetes as per the WHO criteria were evaluated for detail history taking, clinical examination and were subjected to following investigations and questionnaires "International Index of Erectile Dysfunction (IIEF) Scale" and analyse. The questionnaire said to have $60 \%$ specificity as well as $88 \%$ sensitivity. The IIEF- 5 tends to the pertinent areas of male sexual capacity for example erection, sexual desire, intercourse fulfilment, and so forth., and is psychometrically stable. According to this scale, based on the score of IIEF-5 Erectile dysfunction was ordered into 4 severe classes (1-7), moderate (8-11), mild to moderate (12-16), mild (17-21), and no Erectile dysfunction (22-25).

\section{Calculation of Sample Size}

Numaber of patients required for the proper analysis of results will be calculated using following formula,

$$
\mathrm{N}=\mathrm{Z}_{\alpha / 2}{ }^{2 *} \mathrm{P} *(1-\mathrm{P}) / \mathrm{d}^{2}
$$

Where,

$\mathrm{Z}_{\alpha / 2}$ is the level of Significance at $5 \%$ i.e $95 \%$ Confidence interval $=1.96$.

$\mathrm{P}=$ Prevalence of prediabetes in Maharashtra $=12.8 \%=$ 0.128 .

$\mathrm{d}=$ designed error of margin $=7 \%=0.07 \mathrm{n}=1.96^{2} * 0.128 *$ $(1-0.128) / 0.07^{2} \mathrm{n}=90$.

Cases $=100$, Controls $=50$.

The patients, diagnosed as prediabetes as per the WHO criteria were evaluated for detail history taking, clinical examination and were subjected to following investigations and questionnaires "International Index of Erectile Dysfunction (IIEF) Scale" and analyse.

Body mass index (BMI) or Quetelet index is individuals weight divided by the square of his height (metres), it is expressed in units of $\mathrm{kg} / \mathrm{m}^{2}$. Waist Circumference is the stepwise convention for estimating waist circumference as said by WHO that it is to be estimated generally midpoint between the outside limit of end palpable rib and the highest point of the iliac crest. Circumference of the hip is estimated by estimating tape around the amplest bit of the buttocks. Waist/Hip ratio is measured by dividing the measurement of his waist circumference to the hip circumference.

\section{EXPECTED OUTCOMES/RESULTS}

As per previous studies done, it is expected that a higher risk of erectile dysfunction is associated with prediabetes. Prediabetic condition is related to an expanded danger of testosterone inadequacy, without obesity and Metabolic syndrome (MetS). ${ }^{4}$ After adjusting for obesity and Metabolic syndrome, the risk of testosterone deficiency equals that of diabetes. Prediabetic males, maybe at the young age are at an expanded danger of erectile dysfunction and Testosterone deficiency. ${ }^{2}$ Prediabetes is a typical and less often diagnosed clinical condition that is firmly connected with male Sexual function impairment. ${ }^{8}$ Much Milder type of glucose impairment is related to a less fortunate phosphodiesterase 5 inhibitor adequacy in men with erectile dysfunction. ${ }^{9}$

\section{DISCUSSION}

Among the peoples having prediabetes with IGT, there is expanding proof to exhibit a higher recurrence of idiopathic polyneuropathy, sensory neuropathy and small fibre neuropathy. These discoveries give a thought regarding the contribution of the fibres of the small unmyelinated nerve that convey pain, temperature, and control autonomic capacity in prediabetes, which prompts the growth of diabetes. Prediabetes is related to an expanded danger of testosterone inadequacy, without obesity and metabolic syndrome (MetS). ${ }^{10}$ After adjusting for obesity and metabolic syndrome, the risk of testosterone deficiency equals that of diabetes. In prediabetic male adiposity, obesity and high insulin level suppress SHBG level followed by the decreased level of testosterone level. Classification of subjects is based on WHO Asia pacific guidelines according to BMI and waist circumference as Generalized form of obesity, abdominal obesity, isolated generalized form of obesity, isolated abdominal obesity, combined obesity, non-obese subjects..$^{3,5,11}$ Several articles related to various aspects of this study from this institute were reviewed ${ }^{12-14}$. Gaidhane et al. conducted a systematic review on the effect of electronic media on a diet, exercise, and sexual activity among adolescents. ${ }^{15}$

\section{CONCLUSION}

Prediabetes has specified risk associated with Erectile dysfunction.

\section{ACKNOWLEDGMENT}

Authors acknowledge the immense help received from the scholars whose articles are cited and included in references to this manuscript. The authors are also grateful to authors / 
editors / publishers of all those articles, journals, and books from which the literature for this article has been reviewed and discussed.

\section{Conflict of Interest: Nil}

\section{Source of Funding: Nil}

\section{REFERENCES}

1. Corona G, Rastrelli G, Balercia G, Lotti F, Forza A, Monami M, et al. Hormonal association and sexual dysfunction in patients with impaired fasting glucose: a cross-sectional and longitudinal study. J Sexual Med 2012;9(6):1669-80.

2. Rajput R, Banerjee S. Prevalence of Adult-Onset Hypogonadism and Erectile Dysfunction in Males with Prediabetes. Int J Diabet Metabol 2018;21(1-4):2-7.

3. World Health Organization. Waist circumference and waist-hip ratio: report of a WHO expert consultation, Geneva, December 2008.

4. Huang CL, Iqbal U, Nguyen PA, Chen ZF, Clinciu DL, Hsu YH, et al. Using hemoglobin $\mathrm{A} 1 \mathrm{C}$ as a predicting model for the time interval from pre-diabetes progressing to diabetes. PloS one 2014;9(8):e104263.

5. Acharya S, Shukla S, Wanjari A. Subclinical Risk Markers for Cardiovascular Disease (CVD) in Metabolically Healthy Obese (MHO) Subjects. J Clin Diagn Res 2019;13(6).

6. Rathi N, Taksande B, Kumar S. Nerve Conduction Studies of Peripheral Motor and Sensory Nerves in the Subjects With Prediabetes. J Endocrinol Metabol 2019;9(5):147-50.
7. Acharya S, ShuklA S. Metabolic Healthy Obesity-A Paradoxical Fallacy?. J Clin Diagn Res 2018;12(10).

8. Boeri L, Capogrosso P, Ventimiglia E, Schifano N, Montanari E, Montorsi F, et al. Sexual Dysfunction in Men with Prediabetes. Sexual Med Rev 2020;8(4):622-634.

9. Pathak A, Gupta S, Kumar S, Agrawal S. Evaluation of cardiovascular autonomic nervous functions in diabetics: Study in a rural teaching hospital. J Pract Cardiovasc Sci 2017;3(3):150.

10. Bhinder HP, Kamble TK. The study of carotid intima-media thickness in prediabetes and its correlation with cardiovascular risk factors. J Datta Meghe Inst Med Sci Uni 2018;13(2):79.

11. Cladius S, Jadhav U, Ghewade B, Ali S, Dhamgaye T. Study of diabetes mellitus in association with tuberculosis. J Datta Meghe Inst Med Sci Uni 2017;12(2):143.

12. Walinjkar RS, Khadse S, Kumar S, Bawankule S, Acharya S. Platelet indices as a predictor of microvascular complications in type 2 diabetes. Ind J Endocrinol Metabol 2019;23(2):206.

13. Phadnis P, Kamble MA, Daigavane S, Tidke P, Gautam S. Prevalence and risk factors-Hemoglobin A1c, serum magnesium, lipids, and microalbuminuria for diabetic retinopathy: A rural Hospital-based study. J Datta Meghe Inst Med Sci Uni 2017;12(2):121.

14. Dande R, Gadbail AR, Sarode S, Gadbail MP, Gondivkar SM, Gawande M, et al. Oral Manifestations in Diabetic and Nondiabetic Chronic Renal Failure Patients receiving Hemodialysis. J Contemp Dental Pract 2018;19(4):398-403.

15. Gaidhane AM, Sinha A, Khatib MN, Simkhada P, Behere PB, Saxena D, et al. A systematic review on the effect of electronic media on diet, exercise, and sexual activity among adolescents. Ind J Commu Med 2018;43(1): S56. 